\title{
VALUASI EKONOMI KERUSAKAN LINGKUNGAN AKIBAT KEBAKARAN GAMBUT DI DESA MAK TEDUH PROVINSI RIAU
}

\author{
(Economic Valution on Enviromental Damage due to Peat Fire in Mak Teduh Village \\ Riau Province)
}

\author{
Bambang Hero Saharjo ${ }^{1^{*}}$ dan Basuki Wasis ${ }^{1}$
}

(Diterima Desember 2018/ Disetujui Maret 2019)

\begin{abstract}
Peat fires caused negative impact which link to the death of flora, soil damage and smoke disasters.The research proposed to know how big the danger at environment due to forest fire. Unfortunately has so way research found how much money last during burning which link to end damage. Field observation and soil samples were taken through purposive sampling. The result of research show that fire cause a total death of flora and fauna and subsidence of 10-20 $\mathrm{cm}$. This study showed that land fires significantly affected organic C, bulk density, and total microorganisms, and significanlyt effecedt on $\mathrm{pH}$ and respiration parameters. Our results clearly demonstrate the severe enviromental destruction due to on peat fire as it fulfill. The order to know the significance of the vegetation impact of fire that we use PP 4/2004. The order to know the significant of the negative impact of fire the we use PP 4/2004 for soil pH, organic C, bulk density, porosity, water content, total microorganisms, and respiration with the economic valuation ofer, damage due to fire was reached Rp1.765.190.064,--
\end{abstract}

Key words : enviromental damage, economic valution. peat fires, soil properties

\section{PENDAHULUAN}

Kebakaran hutan dan lahan secara ekologis dapat menurunkan kuantitas dan kualitas sumberdaya alam hayati beserta ekosistem yang berfungsi sebagai penyangga kehidupan, antara lain dengan berkurangnya keanekaragaman jenis flora dan fauna sebagai sumber plasma nutfah, kualitas tanah semakin menurun, berubahnya fungsi hidrologis serta pemanasan global. Kerugian lain yang sangat penting adalah kerugian ekonomi lingkungan, berupa polusi asap yang menggangu lingkungan, tidak hanya di Indonesia tetapi juga dirasakan di negara-negara tetangga (Page 2002, Saharjo 2016, Wasis et al. 2018).

Tanah gambut bersifat masam $(\mathrm{pH}<4)$, memiliki kesuburan sangat rendah, tergolong tanah marginal dan rentan terhadap gangguan sehingga usaha peningkatan produktivitas lahan harus diikuti usaha pencegahan kerusakan ekosistem. Kerusakan lahan gambut terutama terjadi karena pembangunan kanal dan penebangan pohon sehingga menyebabkan tanah gambut menjadi kering dan mudah terbakar (Saharjo 2016, Wasis et al. 2018).

Pembakaran tanah gambut oleh masyarakat banyak terjadi pada saat musim kemarau. Pembakaran tanah gambut tersebut umumnya dilakukan terutama pada saat pembukaan lahan. Pembukaan lahan dengan cara membakar dipilih karena murah dan sisa hasil abu

\footnotetext{
${ }^{1}$ Staff Pengajar Dept. Silvikultur, Fakultas Kehutanan IPB

* Penulis korespondensi:

E-mail: bhherosaharjo@gmail.com
}

pembakaran dapat menyuburkan tanah gambut. Penelitian ini menganalisis kerusakan lingkungan dan valuasi ekonomi kerusakan lingkungan pada lahan masyarakat di Desa Mak Teduh Kecamatan Kerumutan Kabupaten Pelalawan Provinsi Riau.

\section{METODE PENELITIAN}

\section{Tempat dan Waktu Penelitian}

Kegiatan penelitian dilaksanakan di tanah gambut Desa Mak Teduh Kecamatan Kerumutan, Kabupaten Pelalawan, Provinsi Riau. Kegiatan penelitian lapangan dilakukan pada bulan Agustus 2015. Analisa statistik uji beda sifat tanah mineral tidak terbakar dan terbakar dan valuasi ekonomi kerusakan lingkungan dilakukan bulan Oktober-Desember 2015.

\section{Alat dan Bahan}

Alat pengambilan data di lapangan adalah alat pengambilan contoh tanah utuh berupa ring sample, untuk pengambilan sampel tanah komposit dengan cangkul, golok, meteran, kantung plastik dan spidol. Bahan utama penelitian sebagai obyek penelitian adalah contoh tanah utuh dan contoh tanah gambut komposit yang berasal dari tanah gambut tidak terbakar (hutan sekunder) dan tanah gambut terbakar di Desa Mak Teduh Kecamatan Kerumutan Kabupaten Pelalawan, Provinsi Riau.

\section{Pengambilan Contoh Tanah}

Pengambilan contoh tanah gambut dilakukan secara purposive sampling pada tanah gambut yang terbakar. 
Pengambilan sampel tanah dilakukan pada dua lokasi yaitu tanah gambut terbakar dan tidak terbakar (hutan sekunder). Setiap lokasi tanah gambut terbakar dan tidak terbakar dibuat petak pengamatan yaitu berukuran masing-masing $20 \mathrm{~m}$ × $20 \mathrm{~m}$. Di dalam plot tersebut dilakukan pengambilan sampel tanah utuh dan tanah komposit pada petak berukuran $2 \mathrm{~m}$ x $2 \mathrm{~m}$ sebanyak 2 ulangan secara acak (Soerianegara dan Indrawan 2005; Wasis 2012).

Pengambilan sampel tanah untuk sifat fisik, sifat kimia dan sifat biologi tanah diambil secara merata pada permukaan tanah kedalaman $0-20 \mathrm{~cm}$. Setiap tempat diambil seberat $1 \mathrm{~kg}$ yang kemudian dikompositkan, dan setelah itu diambil lagi seberat $1 \mathrm{~kg}$. Pengambilan sampel tanah untuk sifat fisik tanah dilakukan pada permukaan tanah kedalaman $0-20 \mathrm{~cm}$. Pengambilan tanah dilakukan secara utuh dengan menggunakan ring sample berdiameter sebesar $7 \mathrm{~cm}$ dengan tinggi sebesar $5 \mathrm{~cm}$ (Wasis 2012 ; Wasis et al. 2018).

\section{Analisis Data}

Data dianalisis secara statistik dengan menggunakan uji perbedaan rata-rata pada interval kepercayaan $95 \%$ (Mattjik dan Sumertajaya, 2013; Stell dan Torries 1991). Parameter untuk sifat fisik tanah yang diuji statistik adalah $\mathrm{pH}, \mathrm{C}$ organik, bulk density, porositas, kadar air, total mikroorganisme dan respirasi. Analisa valuasi ekonomi kerusakan lingkungan akbat kebakaran tanah gambut menggunakan pedoman penghitungan kerugian KLH 2006 (KLH 2006; Wasis et al. 2018b; Adamowicz and Boxall. 2001; Fauzi 2014).

\section{HASIL DAN PEMBAHASAN}

\section{Kondisi Umum Lokasi Penelitian}

Lokasi tanah terbakar awalnya hutan sekunder. Jenis hutan sekunder adalah meranti, mahang dan lainnya dengan potensi biomassa sebesar $138.5 \mathrm{~m}^{3} / \mathrm{ha}$. Jenis tanah pada lahan masyarakat yang terbakar adalah jenis tanah gambut. Pada tanah gambut terbakar telah menyebabkan kematian flora dan fauna sebesar $100 \%$ dan subsiden tanah gambut sebesar $10-20 \mathrm{~cm}$.

Hasil penelitian menunjukkan bahwa kebakaran tanah gambut menyebakan hilangnya flora dan fauna tanah, subsiden, menurunnya fungsi jasa lingkungan, dan matinya mikroorganisme tanah. Hilangnya vegetasi hutan sekunder dan fauna (binatang tanah) akibat kebakaran lahan menyebabkan hilangnya fungsi tata air, serapan karbon, musnahnya flora dan fauna tanah, hilangnya kayu, erosi, sedimentasi sungai dan pencemaran sungai (Wasis et al. 2018b; Wasis 2018). Tutupan tanah oleh vegetasi hutan alam secara umum akan memiliki sifat tanah dan jasa lingkungan yang lebih baik dibandingkan tutupan lahan dengan jenis tanaman perkebunan, dan tanaman pertanian (Wasis 2012). Pembuatan blocking kanal dan penanaman hutan kembali pada tanah gambut terbakar merupakah salah upaya penyelematan tanah gambut (Saharjo et al. 2011, Wasis dan Mulyana 2009).

\section{Sifat Tanah dan Kerusakan Tanah}

Hasil analisa statistk menunjukkan bahwa kebakaran lahan berpengaruh nyata adalah C-organik, bulk density, dan total mikroorganisme, serta berpengaruh sangat nyata untuk parameter $\mathrm{pH}$ dan respirasi (Tabel 1).

Pada tanah gambut yang terbakar terjadi peningkatan $\mathrm{pH}$ tanah secara sangat nyata sebesar 2,42 (58.60\%), penurunan $\mathrm{C}$ organik tanah gambut secara nyata sebesar $25.99 \%(53,71 \%)$, penurunan total mikroorganisme secara nyata sebesar $56.00 \times 10^{6} \mathrm{spk}$ $(95.73 \%)$ dan penurunan respirasi secara nyata sebesar $15.33 \mathrm{mgC}-\mathrm{CO}_{2} / \mathrm{kg}$ tanah/ hari $(69.85 \%)$. Pembakaran tanah gambut telah memperbaiki meningkatkan $\mathrm{pH}$ tanah (mendekati pH netral 7), dan kesuburan tanah gambut. Peningkatan kesuburan tanah diakibatkan abu sisa pembakaran dari biomassa dan hilangnya tanah gambut setebal $10-20 \mathrm{~cm}$ dan tanah gambut yang

Table1 1 Biomassa pada hutan sekunder dan tanah gambut terbakar

\begin{tabular}{llc}
\hline Tutupan lahan & Tipe vegetasi & Biomassa $\left(\mathrm{m}^{3} / \mathrm{ha}\right)$ \\
\hline Hutan sekunder & Meranti, jabon, puspa, mahang dan lain -lain & 138.5 \\
Tanah gambut terbakar & - & 0 \\
\hline
\end{tabular}

Tabel 2 Perubahan parameter (sifat fisik dan kimia tanah) pada hutan sekunder dan tanah gambut terbakar

\begin{tabular}{|c|c|c|c|}
\hline Parameter & Hutan sekunder & Tanah gambut terbakar & Perubahan \\
\hline $\mathrm{pH}$ & $4.13 \pm 0.04 * *$ & $6.55 \pm 0.05$ & $2.42(58.60 \%) \mathrm{d}$ \\
\hline C-Organik (\%) & $48.39 \pm 0.05 *$ & $22.40 \pm 0.36$ & $25.99(53.71 \%) \mathrm{d}$ \\
\hline Bulk Density $\left(\mathrm{g} / \mathrm{cm}^{3}\right)$ & $0.27 \pm 0.01 *$ & $0.37 \pm 0.10$ & $0.10(37.04 \%) \mathrm{d}$ \\
\hline Porositas $(\%)$ & $88.89 \pm 0.39$ & $86.07 \pm 0.23$ & $2.82(3.17 \%) \mathrm{d}$ \\
\hline Air tersedia (\%) & $32.25 \pm 0.05$ & $20.36 \pm 1.59$ & $11.89(36.87 \%) \mathrm{d}$ \\
\hline $\begin{array}{l}\text { Total mikroorganisme (x } \\
\left.10^{6} \mathrm{spk}\right)\end{array}$ & $58.50 \pm 5.25^{*}$ & $2.50 \pm 0.50$ & $56.00(95.73 \%) \mathrm{d}$ \\
\hline $\begin{array}{l}\text { Respirasi } \quad\left(\mathrm{mgC}-\mathrm{CO}_{2} / \mathrm{kg}\right. \\
\text { tanah/ hari) }\end{array}$ & $21.95 \pm 0.03^{* *}$ & $6.62 \pm 0.30$ & $15.33(69.85 \%) \mathrm{d}$ \\
\hline
\end{tabular}

Keterangan:

* : berbeda nyata pada selang kepercayaan $95 \%$ 
mengering setebal $10-20 \mathrm{~cm}$. Tanah yang subur yang memiliki $\mathrm{pH}$ tanah mendekati netral $(\mathrm{pH}$ 6.5-7.5) (Binkley 1987, Hardjowigeno 2003).

Pembakaran tanah gambut meningkatkan bulk density sebesar $0.10 \mathrm{~g} / \mathrm{cm}^{3}$ (37.04\%). Kebakaran tanah gambut menyebabkan tanah gambut menjadi padat. Tanah gambut terbakar menyebabkan kerusakan struktur tanah, matinya flora dan fauna, matinya dan penurunan mikroorganisme tanah. Tanah gambut yang mengalami kerusakan akibat kebakaran bersifat mengkerut dan kemampuan tanah dalam menyimpan air dan hara tidak akan kembali (bersifat irreversible) (Soepardi 1983, Buringh 1983, Hardjowigeno 2003).

Hasil analisa tanah menunjukkan bahwa memang pada tanah terbakar telah terjadi kerusakan lingkungan hidup karena telah memenuhi kriteria baku kerusakan lingkungan hidup (PP Nomor 4 tahun 2001) untuk parameter yaitu $\mathrm{pH}$ tanah, C-organik, bulk density, porositas, kadar air, total mikroorganisme, dan respirasi.

\section{Valuasi Ekonomi Kerusakan Lingkungan}

Berdasarkan hasil penelitian lapangan, analisa laboratorium dan Pedoman Valuasi Ekonomi KLH (2006), maka valuasi ekonomi kerusakan tanah dan lingkungan hidup akibat kebakaralahan di Desa Mak Teduh Kecamatan Kerumutan Kabupaten Pelalawan Provinsi Riau seluas 1 ha dapat dihitung sebagai berikut (KLH 2006, Wasis et al. 2018b, Adamowicz dan Boxall 2001, Fauzi 2014).

\section{Kerugian Ekologis}

\section{Penyimpanan Air}

Sebagai pengganti fungsi gambut sebagai penyimpan air yang rusak maka perlu dibangun tempat penyimpanan air buatan dengan cara membuat reservoir buatan. Resevoir tersebut harus mempunyai kemampuan menyimpan air sebanyak $650 \mathrm{~m}^{3} / \mathrm{ha}$ (Kadar air: 32.25 $\pm 0.05 \%$ ). Karena permukaan tanah gambut yang rusak adalah seluas 1 ha maka reservoir perlu dibuat dengan biaya sebesar:

a. Biaya pembuatan reservoir

Untuk menampung air $650 \mathrm{~m}^{3} / \mathrm{ha}$ diperlukan reservoir berukuran lebar $20 \mathrm{~m}$ x panjang $25 \mathrm{~m}$ $\mathrm{x}$ tinggi $1.5 \mathrm{~m}$. Biaya pembangunan diasumsikan per $\mathrm{m}^{2}=\mathrm{Rp} 100.000,-$.

Per hektar lahan yang hilang, diperlukan biaya $=$ $[(2 \times 1.5 \mathrm{~m} \mathrm{x} 20 \mathrm{~m})+(2 \times 1.5 \mathrm{~m} \times 25 \mathrm{~m})+(20$ m x $25 \mathrm{~m})] \times \mathrm{Rp} 100.000,-/ \mathrm{m}^{2}=635 \mathrm{~m}^{2} \mathrm{x}$ $\mathrm{Rp} 100.000 / \mathrm{m}^{2}=\mathrm{Rp} 63.500 .000,-/ \mathrm{ha}$

Oleh karena itu untuk lahan yang hilang seluas 1 ha diperlukan biaya pembuatannya, adalah = Rp63.500.000/ha x 1 ha = Rp 63.500.000,-

b. Biaya pemeliharaan reservoir

Rp100.000.000/tahun dan untuk 15 tahun menjadi Rp100.000.000 x 15 tahun = Rp1.500.000.000,- (satu milyar lima ratus juta Rupiah).

Bahwa dengan demikian Biaya yang dibutuhkan untuk membangun dan memelihara reservoir buatan seluruhnya adalah Rp 63.500.000,- + Rp1.500.000.000,- = Rp1.563.500.000,-

2. Pengaturan Tata Air

Biaya (uang pengganti) kehilangan fungsi pengaturan tata air akibat tanah gambut terbakar adalah sebesar Rp30.000,- per ha, sehingga biaya yang harus dikeluarkan untuk pengaturan tata air seluas 1 ha adalah sebesar Rp30.000/ha $\times 1$ ha = Rp30.000,-

3. Pengendalian Erosi

Biaya (uang pengganti) akibat kehilangan fungsi pengendalian erosi akibat dari tanah gambut terbakar yang Rp1.225.000,-/ha, sehingga biaya yang dibutuhkan untuk pengendalian erosi untuk lahan seluas 1 ha yang rusak karena pembakaran adalah Rp1.225.000,-/ha x 1 ha = Rp1.225.000,-

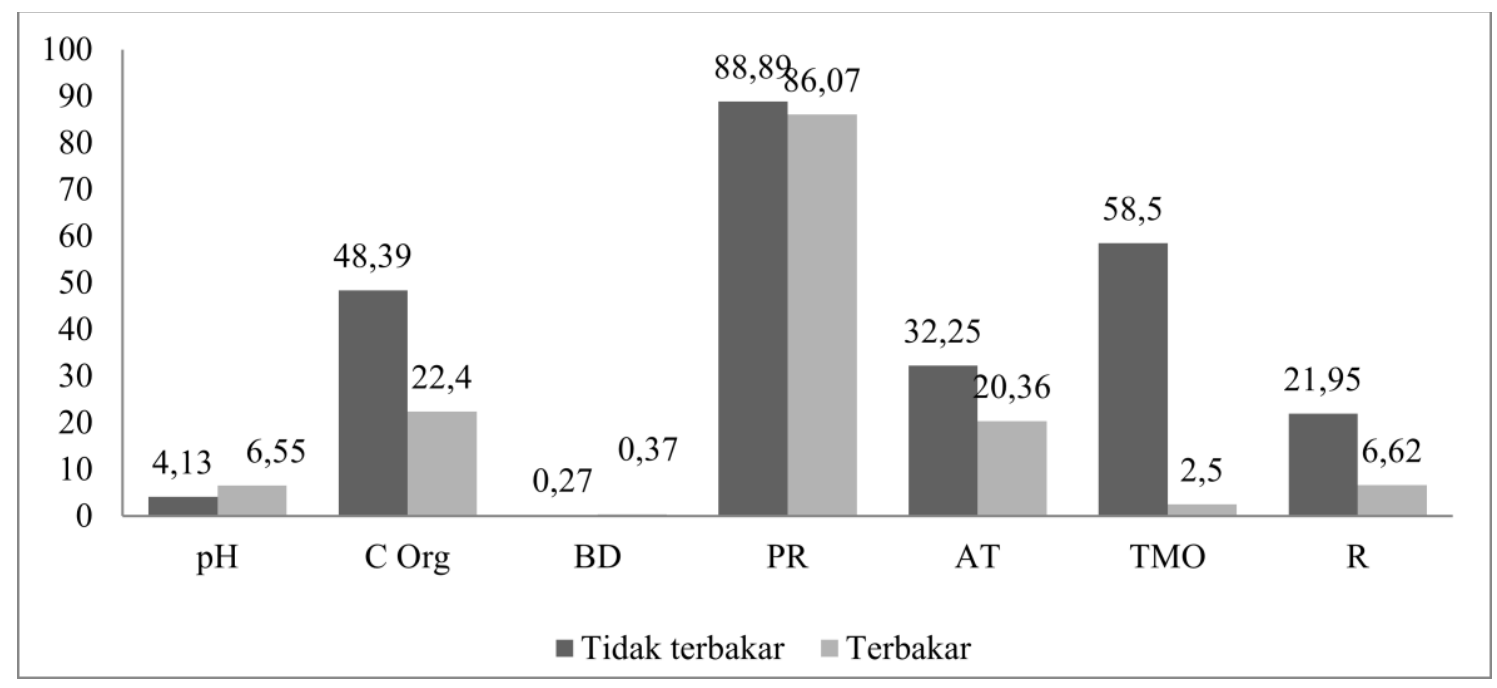

Keterangan: pH (pH), BD (Bulk Density : g/ $\mathrm{cm}^{3}$ ), PR (Porositas : \%), C Org (C Organik : \%), AT (Air tersedia : $\%$ ), TMO (total microorganisme : x $10^{6} \mathrm{spk}$ ), R ( respirasi : $\mathrm{mgC}-\mathrm{CO}_{2} / \mathrm{kg}$ tanah/ hari)

Gambar 1 Perubahaan sifat tanah dan analisa kerusakan tanah gambut akibat terbakar 
4. Pembentuk Tanah

Biaya (uang pengganti) akibat kehilangan fungsi pembentuk tanah akibat rusak karena pembakaran sebesar Rp50.000,-/ha, sehingga biaya yang dibutuhkan untuk pembentukan tanah seluas 1 ha yang rusak adalah: Rp50.000,-/ha $\mathrm{x} 1$ ha = Rp50.000,-

5. Pendaur Ulang Unsur Hara

Biaya (uang pengganti) akibat kehilangan fungsi pendaur ulang unsur hara yang hilang akibat pembakaran sebesar Rp4.610.000,-/ha, sehingga untuk lahan seluas 1 ha maka biaya yang dibutuhkan adalah sebesar: Rp4.610.000,-/ha x 1 ha $=$ Rp4.610.000,-

6. Pengurai Limbah

Biaya (uang pengganti) akibat kehilangan pengurai limbah yang hilang karena rusaknya gambut akibat pembakaran sebesar Rp435.000,-/ha, sehingga untuk lahan seluas 1 ha maka dibutuhkan biaya: Rp435.000/ha x 1 ha = Rp435.000,-

7. Hilangnya Keanekaragaman Hayati

Akibat rusaknya lahan karena pembakaran maka tidak sedikit keanekaragaman hayati yang hilang, untuk itu lahan tersebut perlu dipulihkan. Biaya (uang pengganti) akibat kehilangan fungsi pemulihan bagi keanekaragaman hayati ini sebesar Rp2.700.000,-/ha, sehingga untuk lahan yang rusak seluas 1 ha dibutuhkan biaya : Rp2.700.000,-/ha x 1 ha $=\operatorname{Rp} 2.700 .000,-$

8. Hilangnya Sumberdaya Genetik

Biaya (uang pengganti) akibat hilangnya sumberdaya genetik adalah sebesar Rp410.000,-/ha, sehingga untuk lahan seluas 1 ha diperlukan biaya sebesar : Rp410.000/ha x 1 ha = Rp410.000,-

9. Pelepasan Karbon (Carbon Release)

Akibat adanya pembakaran maka terjadi pelepasan karbon sehingga untuk mengembalikan fungsi sebagai penyerapan karbon, perlu dilakukan kegiatan pemulihan yang menurut perhitungan beberapa pakar dibutuhkan sebesar Rp90.000,-/ton karbon per ha seluas 1 ha dibutuhkan biaya sebesar Rp90.000/ton $\times 3.15$ ton $=$ Rp283.500,-

10 Perosot Karbon (Carbon Reduction)

Dengan adanya pembakaran maka terjadi perosotan karbon tersedia (carbon reduction) sehingga untuk mengembalikan fungsi sebagai penahan karbon dibutuhkan biaya sebesar Rp90.000,- sehingga untuk lahan seluas 1 ha dibutuhkan biaya sebesar: Rp90.000/ha x 0.58275 ton : Rp52.447.5,-

Dengan demikian, biaya total penggantian kerugian ekologis dengan mempertimbangkan 10 parameter di atas adalah sebesar Rp1.573.295.947.5,-- (Satu milyar lima ratus tujuh puluh tiga juta dua ratus sembilan puluh lima ribu sembilan ratus empat puluh tujuh rupiah lima sen )

\section{Kerugian Ekonomis}

Pada bagian kerugian ekonomis ini terdapat dua parameter penting yang patut dipertimbangkan yaitu hilangnya umur pakai tanah pada lahan dan hasil penjualan. Hilangnya umur pakai tanah gambut adalah berkurangnya umur pakai tanah akibat terbakar sehingga kelestarian fungsi lahan tidak tercapai sebagaimana mestinya.

\section{Hilangnya Umur Pakai Tanah}

Akibat kegiatan pembakaran, maka umur pakai lahan menjadi berkurang \pm 15 tahun dibandingkan dengan tanpa bakar. Untuk itu seandainya tanaman mulai berproduksi pada umur 1 tahun, sehingga telah hilang umur pakai lahan selama 14 tahun maka biaya yang telah hilang selama 14 tahun tersebut seandainya lahan tetap berproduksi adalah sebagai berikut:

1) Biaya penanaman untuk 1 ha Rp13.244.983,-

2) Biaya pemeliharaan tahun pertama Rp4.879.848,

3) Biaya pemeliharaan tahun ke-dua Rp4.461.000,-

4) Biaya pemeliharaan tahun ke-tiga Rp6.465.000,-

5) Biaya pemeliharaan tahun ke-empat Rp6.645.000,-

6) Biaya pemeliharaan tahun ke-lima Rp5.810.000,-

7) Biaya pemeliharaan tahun ke-enam dan tujuh Rp67.600.000,

Total biaya yang dibutuhkan untuk selama periode 15 tahun adalah Rp106.996.831,-

Biaya hasil penjualan selama 11 tahun Rp145.200.000,-

Keuntungan yang hilang karena pembakaran Rp38.203.169,-

Total biaya yang harus dikeluarkan dalam mengganti keuntungan yang hilang akibat pembakaran sehingga terjadi hilangnya umur pakai selama 11 tahun adalah sebesar Rp38.203.169,--

Total biaya yang harus dikeluarkan untuk mengganti kerugian/kerusakan yang terjadi secara ekologis serta hilangnya keuntungan secara ekonomis adalah sebesar: Rp145.200.000,- + Rp38.203.169,- = Rp183.403.169 ,(Seratus delapan puluh tiga juta empat ratus tiga ribu seratus enam puluh sembilan rupiah)

\section{Biaya Pemulihan}

Pemulihan lahan yang rusak akibat pembakaran dengan kompos yang diangkut dengan menggunakan truk tronton dengan kapasitas $20 \mathrm{~m}^{3}$ adalah sebagai berikut:

1. Biaya pembelian kompos untuk mengisi 1 ha lahan yang rusak dengan ketebalan rata rata tanah yang terbakar adalah $10 \mathrm{~cm}$ dengan perhitungan biaya sebagai berikut: 1 ha $x 0.1 \mathrm{~m}(10 \mathrm{~cm}) \times 1$ ha $(10.000$ $\left.\mathrm{m}^{2}\right)$ x Rp200.000/触 = Rp.200.000.000,

2. Biaya angkut dengan menggunakan tronton kapasitas angkut $20 \mathrm{~m}^{3} /$ truk maka diperlukan biaya angkut hingga lokasi lahan yang terbakar adalah: $1.000 \mathrm{~m}^{3} / 20 \mathrm{~m}^{3} \times \mathrm{Rp} 800.000$ (sewa truk) = Rp40.000.000 
3. Biaya penyebaran kompos di areal yang terbakar seluas 1 ha $\left(1000 \mathrm{~m}^{3}\right)=20.000$ karung (a 50 $\mathrm{kg}$ )/200/orang x Rp20.000,- x 1 ha = Rp20.000.000,-

4. Biaya pemulihan untuk mengaktifkan fungsi ekologis yang hilang:

a. Pendaur ulang unsur hara Rp4.610.000,-

b. Pengurai limbah Rp435.000,-

c. Keanekaragaman hayati Rp2.700.000,-

d. Sumberdaya genetik Rp410.000,-

e. Pelepasan karbon Rp283.500,-

f. Perosot karbon Rp52.447.5,-

Total Rp8.490.947.5,-

Total valuasi ekonomi kerusakan lingkungan akibat kebakaran tanah gambut yaitu kerugian ekologis + kerugian ekonomis+ biaya pemulihan sebesar 1.573.295.947.5, + Rp 183.403.169 + 8.490.947.5,- = Rp 1.765.190.064,- (Satu milyar tujuh ratus enam puluh lima juta seratus sembilan puluh ribu enam puluh empat rupiah)

\section{SIMPULAN}

Kebakaran gambut menyebabkan kematian total flora dan fauna tanah sebesar $100 \%$ dan subsiden sebesar 10-20 cm. Hasil analisa statistik menunjukkan bahwa kebakaran lahan berpengaruh nyata terhadap Corganik, bulk density, dan total mikroorganisme, serta berpengaruh sangat nyata untuk parameter $\mathrm{pH}$ dan respirasi. Hasil analisa tanah menunjukkan bahwa pada tanah terbakar telah terpenuhinya kerusakan lingkungan hidup karena telah masuk kriteria baku kerusakan lingkungan hidup (PP Nomor 4 tahun 2001) untuk parameter $\mathrm{pH}$ tanah, $\mathrm{C}$ organik, bulk density, porositas, kadar air, total mikroorganisme, dan respirasi. Hasil valuasi ekonomi kerusakan lingkungan akibat kebakaran tanah gambut sebesar Rp 1.765.190.064,- .

\section{DAFTAR PUSTAKA}

Adamowicz V, Boxall P. 2001. Future Directions of Stated Choice Methods for EnvironmentValuation. Vic Adamowicz and Peter Boxall. Choice Experiments: A New Approach to Environmental Valuation, April 10, 2001. London, England.

Binkley D. 1987. Forest Nutrition Management. Duke University, Durham, North Carolina. USA. 290 pp.

Buringh P. 1983. Pengantar Pengajian Tanah-tanah Wilayah Tropika dan Subtropika. Yogyakarta (ID): Gadjah Mada University Press.
Fauzi A. 2014. Valuasi Ekonomi dan Penilaian Kerusakan Sumberdaya Alam dan Lingkungan. Bogor (ID): IPB Press.

Hardjowigeno S. 2003. Ilmu Tanah. Jakarta (ID): Akademika Pressindo.

Mattjik AA, IM Sumertajaya. 2013. Experimental Design with SAS Applications and Minitab. Bogor (ID): IPB Press.

Page S, Siegert F, Rieley JO, Boehmn HDV, Jaya A dan Limin S. 2002. The amount of carbon released from peat and forest fire in Indonesia during 1997. Nature. Vol.42: 61-65

Saharjo BH. 2016. Pengendalian Kebakaran Hutan dan atau Lahan Indonesia. Bogor (ID): IPB Press.

Saharjo BH, Wasis B, Mulyana D. 2011. Canal Blocking of Burn Peat Swamp Forest and It's Future. 5 th International Wildland Fire Conference : Poster Session, South Africa.

Soepardi G. 1983. Sifat dan Ciri Tanah. Fakultas Pertanian IPB Bogor

Soerianegara I, Indrawan A. 2005. Ekologi Hutan Indonesia. Bogor (ID): Fakulats Kehutanan IPB.

Stell RGD, Torries JH. 1984. Principles and Procedurs of Statistic A. Biometrical Approach. Singapore: MacGraw Hill Book Co., Inc.

Soepardi G. 1983. Sifat dan Ciri Tanah. Bogor (ID): Jurusan Ilmu Tanah Fakultas Pertanian IPB.

Stell RGD, Torries JH. 1991. Statistical Principles and Procedures, A Biometric Approach. Jakarta (ID): PT Gramedia Pustaka Utama.

Tan KH. 1995. Enviromental Soil Science. Marcel Dekkker Inc. New York. P 255.

Wasis B, Mulyana D. 2009. Carbon Content at Several Vegetation Type in Ex-PLG Million ha after 10 Years Burnt. Proceedings of IPB research seminar. Bogor

Wasis B. 2012. Soil properties in natural forest destruction and conversion to agricultural land in Gunung Leuser National Park, North Sumatera Province. Journal of Tropical Forest Management (JMHT) XVIII(3) : 206-212

Wasis B, BH Saharjo, F Kusumadewi, NH Utami, MHW Putra. 2018. Analysis of economic valuation of environmental damage due to sand mine in Gumulung Tonggoh, Cirebon District, West Java Province, Indonesia. Archives of Agriculture and Environmental Science 3(4): 360366.

Wasis B. 2018. Impact on Peatland Canal Blocking of Soil Properties in The Eks PLG Milion Ha of Central Kalimantan Province. Advance Research in Agricultural and Veterinary Science (ARAVS) : 5 (3) : 04-11. 